\title{
Estimating continuous monthly baseflow time series and their possible applications in the context of the ecological reserve
}

\author{
VU Smakhtin \\ CSIR: Environmentek, PO Box 395, Pretoria 0001, South Africa
}

\begin{abstract}
The paper describes a simple technique for baseflow separation from continuous monthly streamflow records which are widely available in South Africa. The technique employs a digital filter algorithm, which has been previously used only with more detailed daily streamflow records. The example applications of the separation technique in three gauged catchments are illustrated and its possible applications in the context of groundwater and estuarine components of the ecological reserve determination are discussed.
\end{abstract}

\section{Introduction}

Baseflow is an important genetic component of a streamflow hydrograph, which comes from groundwater and/or shallow subsurface storages. Through most of the dry season of the year, the streamflow discharge is composed entirely of baseflow. During a wet season, discharge is made up of baseflow and quickflow. The latter represents the direct catchment response to rainfall events.

Baseflow may be characterised by its hydrograph, which is derived from the total streamflow hydrograph by various baseflow separation techniques. A variety of event-based separation methods are avaible, which focus on separating baseflow from a flood hydrograph and are eventually aimed at the estimation of the surface runoff component of a flood. The descriptions of such methods may be found in many classical hydrology textbooks and are not examined in this paper.

Other types of baseflow separation techniques are designed to generate a baseflow hydrograph for a long-term period - a year, several years or for the entire period of observations. These techniques (referred to further in the paper as "continuous separation techniques") normally make use of a filtering procedure of some kind, which allows a streamflow time series to be disintegrated into quickflow and baseflow. Perhaps, the most well-known techniques of this type are the UK "smoothed minima" method (FREND, 1989) and "recursive digital filter" (Nathan and McMahon, 1990) although other methods to separate baseflow on a continuous basis have been reported (Sittner et al., 1969; Birtles, 1978; Boughton, 1988; Smakhtin and Hughes, 1993; Sloto and Crouse, 1996). Continuous baseflow separation techniques do not normally attempt to simulate baseflow conditions for a particular flood event, nor are they always appropriate for the identification of the origin of baseflow. These methods are rather aimed at the derivation of objective quantitative indices related to the long-term baseflow response of a catchment (e.g. baseflow index (BFI) - the ratio of baseflow to total streamflow) and at the estimation of continuous time series, which specifically characterise baseflow regime.

Baseflow may be separated from either daily or monthly streamflow time series. Traditionally, most of the continuous separation techniques dealt with the separation of baseflow from

(012) 841-4178; fax (012) 841-2506; e-mail vsmakhtin@ csir.co.za Received 13 July 2000; accepted in revised form 17 January 2001 more detailed daily streamflow records. However, given a wide availability and use of monthly streamflow time series in South Africa, it is logical to develop a technique, which will focus specifically on baseflow separation from monthly flow data. Continuous monthly baseflow time series may be useful for the development of catchment management strategies, the establisment of relationships between aquatic organisms and their environment, the estimation of small to medium water supplies, water quality and salinity management, the estimation of groundwater recharge, etc. This short paper describes one simple technique for continuous baseflow separation from monthly flow time series and discusses some possible applications of this technique in the context of the estimation of the ecological reserve.

\section{Developing and testing the continuous monthly baseflow separation technique}

\section{The description of the algorithm}

The most straightforward approach to estimate a continuous monthly baseflow time series is to identify a suitable daily baseflow separation method and to adjust it for application specifically with monthly flow records. The adjustments are necessary due to the obvious differences in flow variability displayed by daily and monthly flow records. The "prototype" daily separation technique, which has been selected for this study uses a recursive digital filter, which originates from signal analysis. It is designed to separate "highfrequency" signals from "low-frequency" signals. Nathan and McMahon (1990) pioneered the use of this technique in hydrology, considering daily streamflow time series to be a mixture of quickflow (high-frequency signal) and baseflow (low-frequency signal). Smakhtin and Watkins (1997) tested this method intensively on daily streamflow data from South African catchments. In the context of monthly baseflow separation, the formulae of the digital filtering technique may be re-written as:

$$
\begin{aligned}
& \mathrm{q}_{\mathrm{m}}=\mathrm{a} \mathrm{q}_{\mathrm{m}-1}+0.5(1+\mathrm{a})\left(\mathrm{Q}_{\mathrm{m}}-\mathrm{Q}_{\mathrm{m}-1}\right) \\
& \mathrm{QB}_{\mathrm{m}}=\mathrm{Q}_{\mathrm{m}}-\mathrm{q}_{\mathrm{m}}
\end{aligned}
$$

where:

$q=$ part of the monthly flow which can be attributed to high-flow events (quickflow or high-frequency signal), 
$Q=$ total monthly flow (original streamflow time series),

$Q B \quad=$ part of the total monthly flow which could be attributed to baseflow (low-frequency signal),

$a=$ filter parameter

$m \quad=$ the index of the current month in a time series,

$m-1=$ the index of the previous month.

The resultant separated baseflow is constrained so that it is not negative or greater than the original total monthly streamflow in any month.

The required modifications have been made to the previously computerised and formerly widely used daily baseflow separation technique to make it work with monthly flow data. The program forms part of the larger computer package for general time-series processing and analysis, which allows all necessary manipulations to be performed. These manipulations include:

- Conversion of the "raw" monthly flow time series data into a format suitable for baseflow separation. The raw data may either be observed or simulated (e.g. those provided by Surface Water Resources of South Africa 1990 (Midgley et al., 1994)).

- Running the baseflow separation technique on created file(s) with the possibility of modifying the filter parameter value in Eq. (1) for each run.

- Writing resultant monthly baseflow into a separate file for future analysis with other modules provided by the time series computer package, such as flow duration curve, seasonal distribution analysis, annual flow total display, etc.

It is also possible to display simultaneously the separated monthly baseflow time series, original total monthly streamflow time series and baseflow time series obtained from daily separation methods (after accumulation of daily baseflows into monthly baseflow totals). This option is very important and useful for the verification of the proposed technique.

\section{Verification of the separation technique in selected catchments}

The baseflow separation technique has been applied in three small gauged river catchments drawn from different physiographic zones: the Sundays River (the second largest left-hand tributary of the Tugela River (after the Buffalo), which originates in the Low Drakensberg Mountains), the upper Sabie catchment in Mpumalanga (the "wettest" of the three selected catchments, receiving approximately $1250 \mathrm{~mm}$ of rain per annum) and the Koonap catchment in the Eastern Cape Province which drains the mountainous areas of the Winterberg, eventually flowing into the Fish River (the "driest" of the three catchments receiving approximately $600 \mathrm{~mm}$ of rain per annum). The general characteristics of these catchments are summarised in Table 1.

The quality of the monthly baseflow separation technique may be verified against the results of daily baseflow separation, since the latter has already been widely and successfully tested in South Africa and, consequently, initial estimates of the filter parameter $a$ values are available for many catchments. Smakhtin and Watkins (1997) found that the optimal filter parameter values normally fluctuate in the range of 0.985 to 0.995 and recommended the value of 0.995 as being suitable for most of the daily baseflow separations. However, the filter parameter values need to be adjusted if the baseflow estimates from monthly separation are to be made compatible with daily ones. One possible way of adjusting those is

\begin{tabular}{|c|c|c|c|c|}
\hline \multicolumn{5}{|c|}{$\begin{array}{c}\text { TABLE } 1 \\
\text { Study catchments }\end{array}$} \\
\hline Catchment & $\begin{array}{l}\text { Gauge } \\
\text { code }\end{array}$ & $\begin{array}{c}\text { Gauged } \\
\text { area, } \\
\text { km² }^{2}\end{array}$ & $\begin{array}{l}\text { Observed } \\
\text { record }\end{array}$ & $\begin{array}{c}\begin{array}{c}\text { Mean } \\
\text { annual } \\
\text { precipitation } \\
(\mathrm{MAP}), \mathrm{mm}\end{array}\end{array}$ \\
\hline Sundays & V6H004 & 658 & 1954-1997 & 870 \\
\hline Sabie & Х3H006 & 766 & 1958-1998 & 1250 \\
\hline Koonap & Q9H002 & 1245 & $1933-1998$ & 600 \\
\hline
\end{tabular}

through the process of verifying the monthly separation technique, which may be described as follows:

1. Run the baseflow separation technique on observed daily streamflow record using the previously established filter parameter value (e.g. $a=0.995$ ). For each individual month, calculate monthly baseflow values by accumulating separated daily baseflows.

2. Run the baseflow separation technique on observed monthly streamflow record using the initial filter parameter value.

3. Compare the two simulated baseflow time series (the one which originated from monthly streamflows and the one which is the result of accumulating separated daily baseflows) and adjust filter parameter value for monthly separation. The comparison may be based visually and by using some standard criteria of fit between the two baseflow time series (e.g. maximum, minimum, mean, standard deviation, coefficients of determination and efficiency).

4. Repeat the last two steps until the separated monthly baseflow hydrograph corresponds with the accumulated daily baseflows obtained during Step 1.

The process adopted is effectively similar to calibrating the monthly separation procedure against daily baseflow separation results. The results of monthly baseflow separation for three catchments are illustrated in Figs. 1 to 3 by arbitrarily selected 20-year-long extracts from the original total flow and both generated baseflow time series. These results are obtained after several runs of the monthly separation technique for each catchment with different filter parameter values (following the steps outlined above). The final filter parameter value for each catchment is given in the figure captions.

The simulated monthly baseflow hydrographs ("monthly" lines in Figs. 1 to 3) compare favourably in all cases with the results of daily baseflow separation ("accumulated daily" lines in Figs. 1 to 3). This implies that the proposed technique is capable of reproducing the correct pattern of baseflow variability. Therefore, it may be applied to synthetic monthly streamflow time series for quaternary catchments (or their combinations). Since no "calibration" will be possible in such cases, the filter parameter values for the wide application of this technique may need to be regionalised or typified for similar hydrogeological and/or climatic conditions. This regionalisation/typification may need to be investigated separately. But, as a general rule, the filter parameter value of 0.925 is envisaged to be a good starting point for most of the monthly baseflow separations. It is likely to be applicable for monthly baseflow separations in regions where MAPs are in the range of approximately 600 to $1100 \mathrm{~mm}$. In semi-arid and arid regions with MAPs of less than an arbitrary threshold of $600 \mathrm{~mm}$, 
Figure 1

The results of continuous

baseflow

separation for the

Sundays River at gauge V6H0O4 (filter parameter value 0.930 )
Figure 2

The results of continuous

baseflow

separation for the

Sabie River at

gauge $\mathrm{X} 3 \mathrm{HOO6}$ (filter parameter

value 0.910)

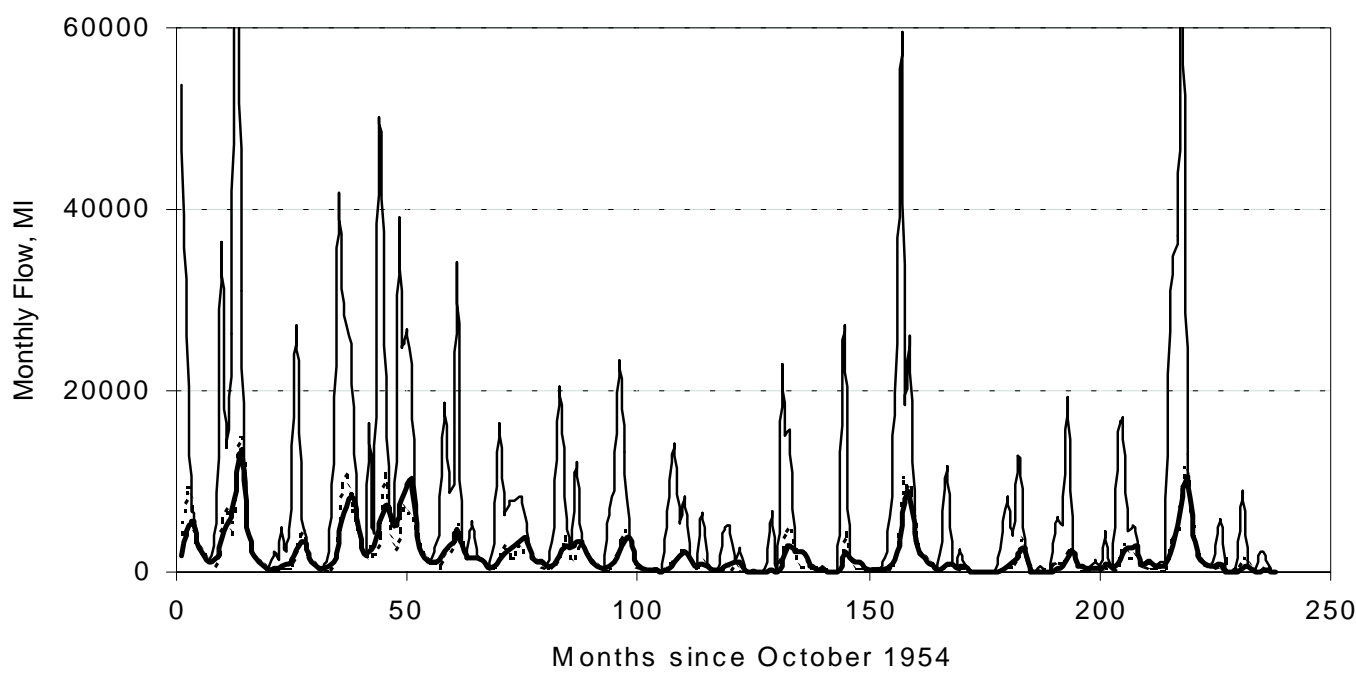

Total Monthly -..... - Accumulated Daily

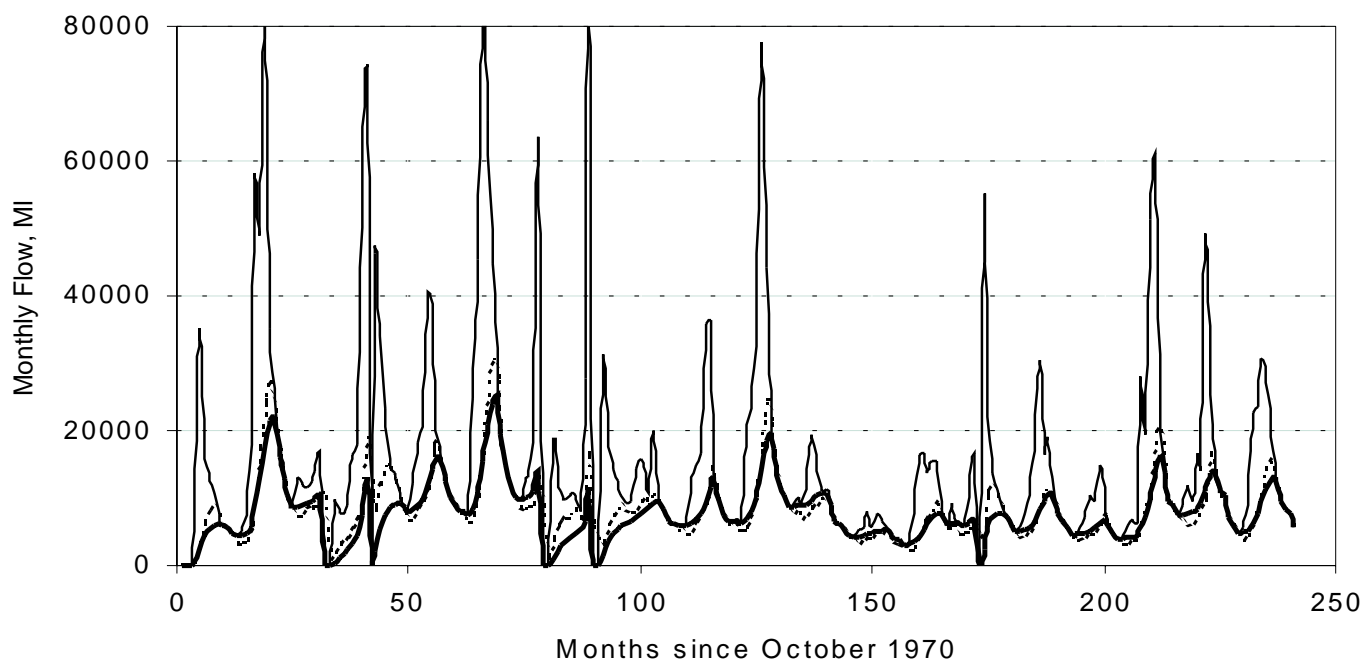

Total Monthly ....... Accumulated Daily

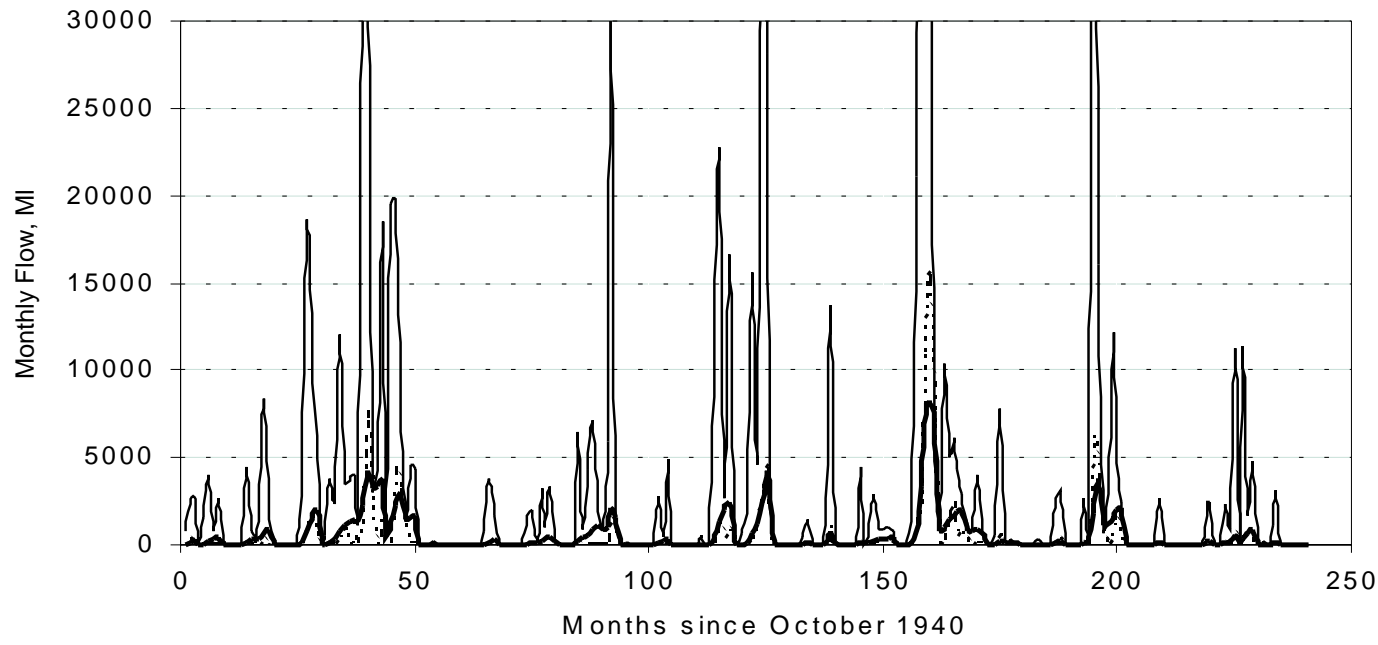

Total Monthly

Accumulated Daily 
the filter value may be increased by about $2 \%$ and in regions where MAP is over $1100 \mathrm{~mm}$, the filter value may be decreased similarly.

\section{Possible applications of continuous monthly baseflow separation in the context of the ecological reserve}

The applications of baseflow time series could be numerous. This section discusses only a few possible applications in the specific context of ecological reserve determination. The National Water Act of 1998 places emphasis on the protection of water resources for their sustainable utilisation, which is reflected in the subsequent development of resource directed measures (RDM). A major component of the RDM is the determination of the ecological reserve, which entails investigation of the relationship among major interactive components of the water cycle, namely surface water bodies and groundwater. Depending on the purpose and/or significance of the resource in question, the reserve determination required may be done at either a desktop, rapid, preliminary or comprehensive level. The distinction is also made between quantity and quality components of the reserve. The reserve is determined for different types of water bodies (rivers, estuaries, wetlands, groundwater) and some of the methodologies developed to date (e.g. reserve determination for rivers) make extensive use of the available streamflow time series information. At desktop and rapid levels of river reserve determination, the time series used are of monthly resolution (those which are routinely available from Midgley et al. (1994) for each of the approximately 2000 small and normally ungauged drainage subdivisions throughout the entire country - quaternary catchments). It is important to ensure that the developing techniques for reserve determination of other water bodies are ideally compatible with each other, or at least are using a similar information base where appropriate. In this context, the use of quaternary catchment synthetic monthly streamflow time series and baseflow time series derived from them in other reserve determination methods is one obvious approach.

\section{Groundwater quantity component of the reserve}

A conceptual framework for the determination of the groundwater component of the ecological reserve was formulated by Braune et al. (1999). Groundwater interaction with surface water bodies has been identified as one issue, which is poorly understood in South Africa at present. The incorporation of groundwater and surface water relationships into the developing reserve methodology is seen as one of its major components. The other identified necessity is to add a dimension of temporal variability to groundwater reserve methodology. Both issues could certainly be addressed with different degrees of detail required at different levels of reserve determination. But in any case, it is the geohydrological time series of baseflow, groundwater storage and recharge, which should become part of the methodology.

The first time series, which needs to be estimated, is the baseflow time series, which may be considered to be the outflow from groundwater storage. The technique for continuous baseflow separation described above may be applied to synthetic streamflow time series available from Midgley et al. (1994) for all quaternary catchments. The result of applying this technique to available synthetic flow data may be the baseflow time series for each quaternary catchment in the country (or for those quaternary catchments (or their combinations) where the estimation of baseflow is feasible).

Groundwater storage time series may then be estimated from baseflow for each month using, for example, the principle of a linear reservoir. The theory of a linear reservoir assumes that storage is proportional to outflow (in this case - to baseflow) with a proportionality (retention) constant. Retention constants may be estimated on a regional basis from previous low-flow studies (e.g. Smakhtin and Watkins, 1997). Retention constant and other model parameters may need to be quantified on a quaternary catchment scale of spatial resolution. If a distinction needs to be made among the different types of baseflow (e.g. outflow from channel bank storage or unconfined aquifers), a multistorage model may be more appropriate. In such cases, the baseflow will depend not only on the total volume of subsurface storage, but also on the distribution of this volume between dominant subsurface "reservoirs". This would certainly add complexity to the overall "time-series-basedgroundwater-reserve" methodology, but its general principles are likely to remain the same. The low-confidence estimates of groundwater recharge may perhaps be obtained as the difference between the current storage and the storage remaining from the previous month, but alternative approaches may also need to be examined and utilised. The component geohydrological time series (baseflow and storage) will represent natural (reference) conditions (since initially used synthetic monthly streamflows available from Midgley et al. (1994) also reflect natural catchment conditions).

Similar steps may be performed when river reserve time series - instream flow requirements (IFRs) are used instead of reference natural streamflow time series. The corresponding groundwater storage time series will then represent the groundwater reserve. These storages may provisionally be called "IFR driven". Two component reserve time series (river and groundwater) are, therefore, dependent. In this example, the assumption is that IFRs (river reserve flows) determine the extent to which groundwater resources may be impacted in the absence of any surface water resource development (the impacts may include groundwater pumping and recharge reduction due to catchment changes, etc.). In other words, IFRs determine the groundwater storages, which are necessary to maintain them. Baseflow time series generated under alternative assumptions may also be used as inputs to the proposed algorithm. In general, conceptualisation of links between river reserve and groundwater reserve needs more insight and should be examined separately.

The time series of differences between natural (reference) storages (or similarly estimated present-day storages) and the "IFR-driven" storages, in principle, represent a monthly step time series of exploitable groundwater and, as such, may be used to estimate the groundwater yield similarly to the estimation of river yield by surface water yield models. The storage (reserve) time series may be used to estimate the impacts on groundwater yield.

The described concept starts from estimating the baseflow time series and baseflow separation is, therefore, the key to the estimation of other geohydrological monthly time series. It may effectively open the way to the development of the nation-wide database of synthetic geohydrological time series characteristics (which, as opposed to the database of surface water characteristics, does not exist at present).

\section{Estuarine quantity component of the reserve}

The recommended procedures for the estimation of estuarine flow requirements at the desktop and rapid levels, although not developed in detail, do however stipulate that both the seasonal baseflow component of inflow to an estuary and floods of the magnitude of 1:5 years and greater should not be included in the allowable reduction from natural total inflow. The sum of these two components 
represents (in terms of the desktop and rapid reserve determinations) a minimum requirement, which is necessary for an estuary to maintain its ecological equilibrium, regardless of the environmental management class (EMC) in which the estuary is to be maintained. The remaining flow component is subject to allowable flow reductions, to a level, which depends on the EMC, type of an estuary and its sensitivity to flow reduction. The present lowconfidence methods of estuarine reserve estimation explicitly require the knowledge of the baseflow regime, and the continuous baseflow separation technique described in this paper is directly relevant in this context.

There are about 150 "coastal" quaternary catchments in South Africa, which normally contain at least one estuary. At the same time, there are many more estuaries in the country. Some of them are very small and there may be several estuaries in one quaternary catchment. Individual small estuaries may, however, have a very high ecological importance and conservation value. Synthetic monthly cumulative streamflow records for each quaternary catchment (including coastal ones) are available (e.g. Hughes and Munster, 1999). These records represent a sum of monthly streamflow time series for all quaternary catchments upstream of the point of interest and have been adjusted for transmission losses using a simple transmission loss calculation procedure. These cumulative records could be used directly with the baseflow separation technique described in this paper to estimate the time series of the baseflow component required by the low confidence methods of the estuarine reserve. Wherever there is more than one estuary in a quaternary catchment, the original synthetic monthly streamflow time series should first be apportioned in accordance with the size of catchment areas of subquaternary streams.

While it is in any case a rather straightforward procedure to separate baseflow time series for any estuary once the total monthly inflow data are available, the problem of separating required high flows of a certain magnitude (e.g. 1 in a 5-year period and larger floods as required by the estuarine reserve) from monthly time series is not a trivial one. It has not been addressed in this paper, which focuses specifically on baseflow separation, and could be a challenge for future research in a broader context of hydrological time series construction.

\section{Conclusions}

The technique for baseflow separation from monthly streamflow records has been developed and tested in three gauged river catchments in South Africa. It has been illustrated that the technique is capable of reproducing the correct pattern of baseflow variability by comparison of the separated monthly baseflow hydrographs with the results of more detailed "daily" baseflow separation previously extensively tested in South African conditions.

The developed monthly baseflow separation technique opens the way to the incorporation of the time series concepts into developing estimation methods of the groundwater quantity component of the ecological reserve. With the help of this technique, the problem of groundwater reserve quantification may be approached from the "hydrological side" - using the widely available synthetic monthly streamflow time series data. Other geohydrological time series which is important in the context of the groundwater reserve (e.g. storage), may be quantified using the principle of a linear reservoir. The general framework of such quantification has been suggested. The developed separation technique is also directly applicable to the quantification of the baseflow component of the estuarine reserve.

The application of the suggested baseflow separation technique is not limited to the context of the ecological reserve only, but could also assist in the solution of other geohydrological and hydrological problems, where the knowledge of subsurface discharge into a stream is important.

\section{Acknowledgements}

The author is grateful to Christine Colvin, David le Maitre and Julian Conrad (all from CSIR: Environmentek, Stellenbosch branch) who made valuable comments to the draft of this paper.

\section{References}

BIRTLES AB (1978) Identification and separation of major base flow components from a stream hydrograph. Water Resour. Res. 14 791- 803 .

BOUGHTON WC (1988) Partitioning streamflow by computer. Inst. Eng. Civ. Eng. Trans. CE30 (5) 285-291

BRAUNE E, XU Y, VAN DER VOORT I, CONRAD J, COLVIN C, LE MAITRE D, VAN TONDER GJ, CHIANG WH, ZHANG J, WRITE K, HUGHES S and PIETERSEN K (1999) Comprehensive Determination of Water Resource Reserve: Groundwater Component. (Zero Version).

FREND (FLOW REGIMES FROM EXPERIMENTAL AND NETWORK DATA) (1989) I: Hydrological Studies. II: Hydrological Data. Wallingford, UK.

HUGHES DA and MUNSTER F (1999) Hydrological Information and Techniques to Support the Determination of Water Quantity Component of the Ecological Reserve for Rivers. WRC Report No 867/3/99.

MIDGLEY DC, PITMAN WV and MIDDLETON BJ (1994) Surface Water Resources of South Africa 1990. WRC Report No 298/5/94.

NATHAN RJ AND McMAHON TA (1990) Evaluation of automated techniques for base flow and recession analyses. Water Resour. Res. 26 1465-1473.

SITTNER WT, SCHAUSS CE and MONRO JC (1969) Continuous hydrograph synthesis with an API-type hydrologic model. Water Resour. Res. 5 1007-1022.

SLOTO RA and CROUSE MY (1996) HYSEP: A Computer Program for Streamflow Hydrograph Separation and Analysis. U.S. Geological Survey Water-Resources Investigations Report 96-4040. 46 pp.

SMAKHTIN VY and HUGHES DA (1993) The application of automated procedures for low-flow analysis of South African rivers. Proc. of the 6th S. Afr. Natl. Hydrol. Symp. Pietermaritzburg, South Africa. Vol 1 329-336.

SMAKHTIN VY and WATKINS DA (1997) Low Flow Estimation in South Africa. WRC Report No 494/1/97. 